\title{
Don't miss the obvious: The dangers of lateral pericardial defects
}

Rakesh M. Suri, MD, DPhil, Hoda Javadikasgari, MD, Tomislav Mihaljevic, MD, Stephanie Mick, MD, and A. Marc Gillinov, MD

From the Department of Thoracic and Cardiovascular Surgery, Heart and Vascular Institute, Cleveland Clinic, Cleveland, Ohio.

Disclosures: R.M.S. has institutional research agreements with Sorin, St Jude, Edwards, and Abbott. A.M.G. is a consultant to AtriCure, Medtronic, St Jude Medical, Edwards Lifescience, Abbott Vascular, On-X, and ClearFlow, and receives research support from St Jude Medical. All other authors have nothing to disclose with regard to commercial support.

Received for publication June 13, 2016; accepted for publication June 16, 2016; available ahead of print July 14, 2016.

Address for reprints: Rakesh M. Suri, MD, DPhil, Department of Thoracic and Cardiovascular Surgery, Heart and Vascular Institute, Cleveland Clinic, 9500 Euclid Ave, Cleveland, OH 44195 (E-mail: surir@ccf.org). J Thorac Cardiovasc Surg 2016;152:e83-4

$0022-5223 / \$ 36.00$

Copyright (C) 2016 by The American Association for Thoracic Surgery

http://dx.doi.org/10.1016/j.jtcvs.2016.06.024

Patient safety and the quality of clinical outcomes remain forefront in our minds as cardiac surgeons. Although the standard sternotomy incision is a well-proven access route to the heart, the ability to perform cardiac surgical procedures through smaller incisions, with less patient debility, has changed the specialty and will undoubtedly define our profession's evolution over the next decade. Minimally invasive techniques have allowed heart surgeons to effect the same technical procedures that we are accustomed to, while obviating the need to touch and see the cardiac structures directly by using long instruments and high-definition video-assisted imaging. The most successful programs worldwide have been able to perform each of the important steps of well-vetted traditional operations exactly as

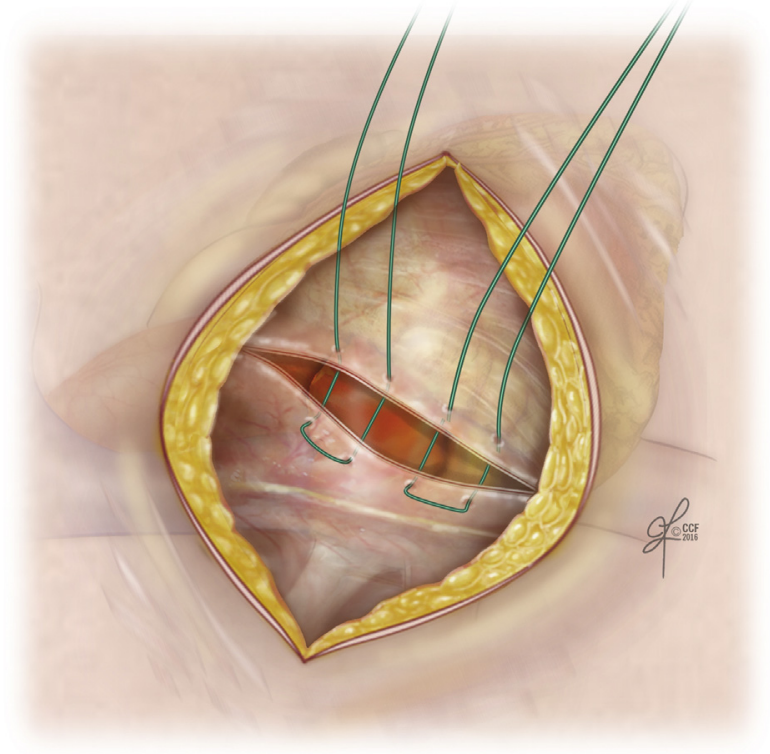

FIGURE 1. Closure of lateral pericardiotomy incision.

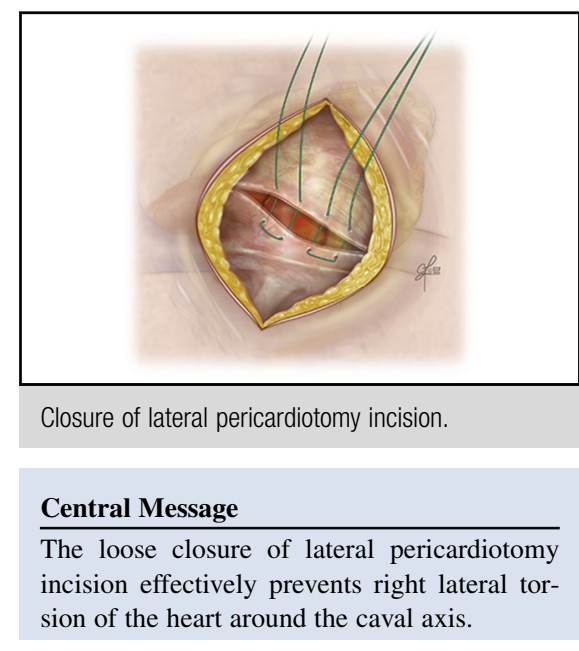

See Article page e79.

through sternotomy without introducing new sources of patient morbidity. ${ }^{1-3}$

Right chest approaches to the mitral valve necessitate a longitudinal lateral pericardiotomy created 3 to $4 \mathrm{~cm}$ anterior to the phrenic nerve running parallel to it from the inferior vena cava to the ascending aorta. After completion of the mitral valve repair and removal of the cardioplegia/vent assembly from ascending aorta, hemostasis is secured in the pericardial space from cardiotomy closure sites and intrathoracically from port access sites. ${ }^{4}$ Closure of the pericardium has been advocated to prevent torsion of the heart around the caval axis, thereby decreasing the risk of catastrophic hemodynamic collapse caused by strangulation of venous return to the right heart. ${ }^{5}$ This step is quick, simple, and effective. Elapavaluru and colleagues ${ }^{6}$ report the diagnosis and management of cardiac torsion into the right chest after robotic mitral valve repair. The condition was identified on return of the patient to the intensive care unit and was managed by hyperinflation of the lung and chest percussion.

The case report highlights, in our view, an important learning point for new teams in the technical performance of minimally invasive cardiac surgical procedures. Manipulation of various intrathoracic structures in nonstandard ways necessitates a redefinition of the learning curve, potentially exposing the patient to morbidity and mortality risks that may not necessarily be associated with the parent procedure. To be specific, the midline pericardiotomy used in traditional sternotomy approaches to the mitral valve do not allow the 
heart to rotate out of the pericardial cradle after chest closure. The same is not true of lateral pericardiotomy incisions, which provide little to no support to maintain the heart within in the native pericardial well. It is for this reason that we think that the pericardium should at least be partially approximated. Stated differently, there is essentially no reason to avoid closing a defect in the lateral pericardium that a heart may herniate through after completion of minimally invasive cardiac surgery. The closure need not be complete or result in tight approximation of the 2 cut edges of the pericardium directly; however, it must effectively prevent right lateral torsion of the heart around the caval axis (Figure 1). This important safety message is the critical element that must be highlighted when considering the referenced case report.

\section{References}

1. Suri RM, Dearani JA, Mihaljevic T, Chitwood WR Jr, Murphy DA, Trento A, et al. Mitral valve repair using robotic technology: safe, effective, and durable. J Thorac Cardiovasc Surg. 2016;151:1450-4.

2. Suri RM, Taggarse A, Burkhart HM, Daly RC, Mauermann W, Nishimura RA, et al. Robotic mitral valve repair for simple and complex degenerative disease: midterm clinical and echocardiographic quality outcomes. Circulation. 2015; 132:1961-8.

3. Murphy DA, Moss E, Binongo J, Miller JS, Macheers SK, Sarin EL, et al. The expanding role of endoscopic robotics in mitral valve surgery: 1,257 consecutive procedures. Ann Thorac Surg. 2015;100:1675-82.

4. Siwek LG, Reynolds B. Totally robotic mitral valve repair. Oper Tech Thorac Cardiovasc Surg. 2008;12:235-49.

5. Mamoun NF, Koch CG, Gillinov AM. Cardiac herniation through a pericardial defect after minimally invasive mitral valve surgery. A A Case Rep. 2013;1:79-81.

6. Elapavaluru S, Matyi M, Crouch R, Raina A, McGregor W. Impending cardiac herniation following robotic mitral valve repair: a case report and review of the literature. J Thorac Cardiovasc Surg. 2016;152:e79-82. 